\title{
Steam-Reforming Characteristics of Heavy and Light Tars Derived from Cellulose*
}

\author{
Hirotatsu WATANABE**, Yosuke MORINAGA** and Ken OKAZAKI** \\ ** Department of Mechanical and Control Engineering, Graduate School of Engineering, \\ Tokyo Institute of Technology \\ 2-12-1-16-7, Ookayama, Meguro-ku, Tokyo, Japan \\ E-mail: watanabe.h.ak@m.titech.ac.jp
}

\begin{abstract}
In this study, tar formation and steam-reforming mechanisms are discussed by separating the tars into heavy, middle, and light tars. Cellulose was heated in a drop-tube furnace under an $\mathrm{Ar}$ or $\mathrm{Ar} /$ steam atmosphere. After the tars were passed through the furnace for thermal cracking and polymerization, they were trapped by filters set at different temperatures $(573,393$, and $273 \mathrm{~K})$, and were respectively defined as heavy, middle, and light tars. Incondensable volatiles and gaseous products were measured using gas chromatography with thermal conductivity (GC-TCD), and flame ionization (GC-FID) detectors. The middle and light tars obtained under an Ar atmosphere were first characterized using time-of-flight mass spectrometry (TOF-MS). The analysis showed that the middle tar did not contain any low-boiling-point light tar components, while the light tar did contain them. It was also found that complex species in the tars were separated to a certain degree by changing the trap temperature. Moreover, the formation of heavy tar was quite different from that of the light tar. With increasing temperature, the formation of heavy tar was inhibited, while that of the light tar was enhanced during pyrolysis. The steam-reforming characteristics of these tars were also different. The heavy tar was barely reformed at a low temperature of $873 \mathrm{~K}$, even with a long residence time, while the middle tar was well reformed by steam. While it was difficult to describe the tar formation and steam-reforming characteristics when the tar was considered as a single condensable matter, the tar formation and steam-reforming characteristics were clarified by separating the tars. This study shows that, to prevent tar emissions, the formation of heavy tar, which barely reacts with steam, should be inhibited during pyrolysis by controlling the heating.
\end{abstract}

Key words: Biomass, Heavy Tar, Steam Reforming, Cellulose, Tar Separation

\section{Introduction}

The formation of tar during biomass gasification is one of the primary obstacles preventing the commercialization of biomass gasification processes. The biomass-derived tars consist of a wide range of condensable hydrocarbon- and oxygen-containing compounds, that are mostly aromatics and complex poly-aromatic hydrocarbons ${ }^{(1)}$. To achieve high efficiencies, the tar must be removed before the syngas $\left(\mathrm{CO}\right.$ and $\left.\mathrm{H}_{2}\right)$ is used for internal combustion engines or fuel cells. Therefore, numerous investigations of tar formation, reforming, and cracking have been conducted. There is a substantial amount of literature that discusses tar characteristics by defining tar as the sole condensable matter collected in the tar trap ${ }^{(2-7)}$; however, the complex composition of biomass tars makes it difficult to understand the tar reaction mechanisms when tar is considered as the sole

${ }^{*}$ Received 6 Mar., 2012 (No. 12-0141) [DOI: 10.1299/jtst.7.180]

Copyright $\odot 2012$ by JSME 
condensable matter. Therefore, some studies have used model tar compounds such as benzene $^{(8)}$, toluene ${ }^{(9-10)}$, and naphthalene ${ }^{(11)}$ to clarify the tar decomposition mechanism. In addition, a large number of polar organic compounds in tars have been examined by mass spectrometric (MS) analysis ${ }^{(12,13)}$. The formation of levoglucosan, 5-hydroxymethylfurfural, and furfural (the main products) was detected, and detailed chemical pathways for the decomposition of cellulose and levoglucosan were proposed ${ }^{(12)}$. However, the detected species in tar accounted for only 70-80\% of tar, and thus, all the species in tars have not been identified by MS because of the complexity of heavy tars. Hosoya et al. identified a large number of organic compounds in tars derived from lignin using gel permeation chromatography (GPC) and gas chromatography-mass spectrometry (GC-MS); however, dimers with molecular weights greater than 200 were not identified ${ }^{(14)}$. In addition to the tar characterization, tar condensing temperature is important because tars are condensed on low temperature part in an actual gasifier. Therefore, the formation characteristics of tars classified by condensing temperatures are also useful for developing a biomass gasifier.

Steam gasification of biomass has been extensively studied in various reactors ${ }^{(2,5,10,15)}$; however, the steam-reforming characteristics of heavy tar have not been clarified. Therefore, to better understand the mechanism of tar formation and steam reforming, the characteristics of heavy tar should be studied. Recently, several researchers defined heavy $\operatorname{tar}^{(16-18)}$, like as the eventual residue after some solution and drying procedures ${ }^{(16)}$. They investigated the cracking of heavy tar using a catalyst under an inert gas; however, little effort has been made to study the steam reforming of heavy tar.

In this study, tars collected using filters set at different temperatures $(573,393$. and $273 \mathrm{~K})$ are defined as heavy, middle, and light tar, respectively. This tar separation is suited for investigating the formation of heavy tar, which is difficult to analyze with MS, and tars classified by condensing temperature. The formation, thermal cracking, and steam reforming mechanisms for each tar are discussed. In addition, MS analysis is used for the identification of the chemical compounds in the middle and light tars.

\section{Experiment}

Figure 1 shows a schematic diagram of the experimental setup. The reactor was made from a quartz tube with an internal diameter of $26 \mathrm{~mm}$ and a total length of $2000 \mathrm{~mm}$.

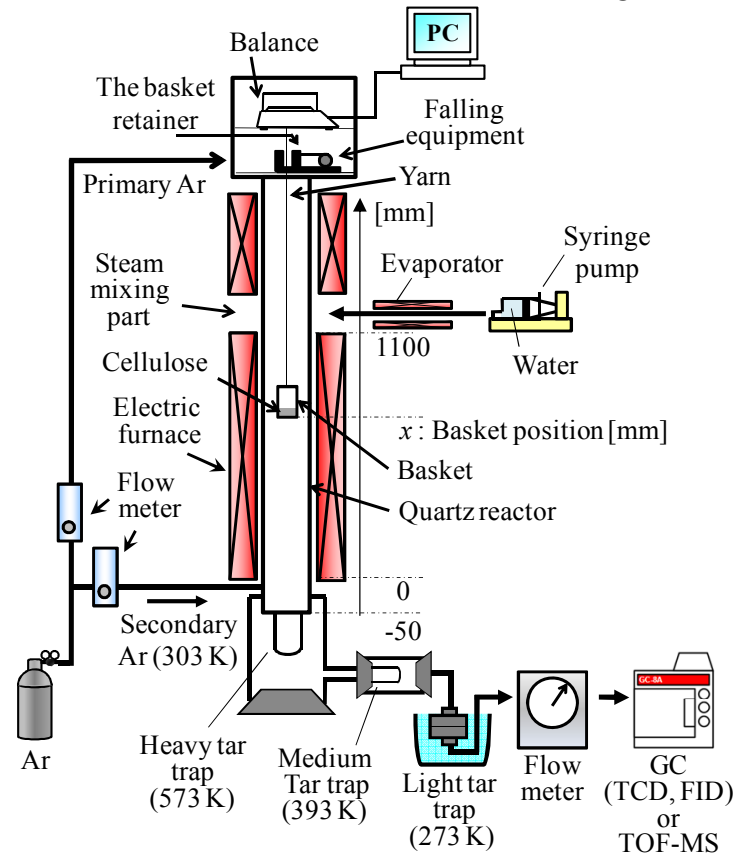

Figure 1 Schematic diagram of experimental appratus 
Commercially available cellulose powder (C6413, microgranular, Sigma-Aldrich) was used as the cellulose sample. According to Ref. ${ }^{(19)}$, about $50 \%$ of the woody biomass consists of cellulose. Therefore, tars derived from cellulose are close to those derived from woody biomass. In the pyrolysis experiment, primary Ar was introduced into the top of the reactor at a flow rate of $0.5 \mathrm{~L} / \mathrm{min}$. Secondary Ar was introduced into the bottom of the reactor to quench the reaction. The flow rate of the secondary Ar varied with the furnace temperature to maintain a constant tar trap temperature to be constant. In the steam-reforming experiment, the volume flow ratio of steam to primary Ar was 1:4. In addition to the primary Ar, which was introduced at a flow rate similar to that in the pyrolysis experiment, steam was introduced through a steam-mixing device with many holes that provided uniform steam. The gas temperature varied from 873 to $1273 \mathrm{~K}$. The gas temperature in the reactor was measured using a suction pyrometer with a diameter of $8 \mathrm{~mm}$. An R-type thermocouple was shielded by an alumina tube to minimize any radiative heat errors. The temperature history of sample during heating was also measured by attaching a K-type thermocouple to the basket.

After the air was displaced with an $\mathrm{Ar}$ or Ar/steam atmosphere and the gas temperature reached a steady state, a basket with an internal diameter of $21 \mathrm{~mm}$ and a total length of 36 $\mathrm{mm}$ containing-100 $\mathrm{mg}$ of cellulose powder was dropped to a predefined position $(x)$ with the falling equipment. The falling equipment made the basket drop by dragging the basket retainer using an electric motor. By varying the basket position, the residence time of the volatile matter was controlled without changing the gas flow rate. Then, the sample was rapidly heated in the quartz reactor, and gaseous products and tars were released during heating. After the tars passed through the reactor and underwent thermal cracking, polymerization, and steam reforming, they were trapped by filters set at different temperatures. Levoglucosan is a major component of tar and is considered as an important intermediate in cellulose pyrolysis ${ }^{(13,20)}$. Some researchers have investigated the pyrolytic reaction pathways of levoglucosan; however, the reaction pathways of dimers with molecular weight greater than that of levoglucosan have not been clarified. In this work, heavy tar was defined as the condensable matter with a boiling point greater than that of levoglucosan. Because the boiling point of levoglucosan is approximately $612 \mathrm{~K}^{(21)}$, the filter temperature for heavy tar was set to $573 \mathrm{~K}$ to trap levoglucosan and condensable matter with boiling points greater than levoglucosan. The molecular weight of most of the heavy tar collected by the filter is expected to be greater than that of levoglucosan, although it is not necessarily appropriate to suggest that the boiling point is related to the molecular weight. The filter temperature for the middle tar was set to $393 \mathrm{~K}$ to prevent water condensation. The light tar and water were trapped using a filter at $273 \mathrm{~K}$. Incondensable volatiles and gaseous products defined as gas products, were collected by the gas pack $(5 \mathrm{~L})$. The remaining residue in the basket was defined as char. Gaseous products $\left(\mathrm{CO}, \mathrm{CH}_{4}, \mathrm{CO}_{2}\right.$, $\mathrm{C}_{2} \mathrm{H}_{4}, \mathrm{C}_{2} \mathrm{H}_{6}$ and $\mathrm{C}_{2} \mathrm{H}_{2}$ ) were measured using a GC-FID (GC-8APF, Shimadzu Corp.) equipped with a methanizer, and $\mathrm{H}_{2}$ was measured with a GC-TCD (GC-8APT, Shimadzu Corp.). In addition, the heavy tar had to be separated from the soot. To investigate soot formation, other experiments were performed, in which the filter was set at $x=50 \mathrm{~mm}$ (the upstream part of the heavy tar filter, and the temperature is larger than $700 \mathrm{~K}$, thereby, little tar is condensed) in the reactor; however, the amount of soot collected by the filter was negligible in this study.

To gain additional information, the tar was analyzed by time of flight mass spectrometry, TOF-MS (LICA-MS350, TOYAMA). Because the tube connected to the detector of the mass spectrometer was heated at $423 \mathrm{~K}$, MS analysis of the light and middle tars was possible. However, to avoid the deposition, heavy tar analysis was not performed. The analysis procedures for the middle and light tars were as follows. First, a mixture of the light tar and gas products was measured by TOF-MS by excluding the light tar filter shown 
in Figure 1. By extracting the gas products measured by GC from the above mixture, the light tar was identified. Similarly, a mixture of the middle tar, light tar, and gaseous products was analyzed by TOF-MS by excluding the filters for the middle and light tars. Then, the middle tar was obtained by extracting the light tar components and the gas products from the mixture.

\section{Results and discussion}

Figure 2 shows the temperature profiles in the reactor under an Ar atmosphere. A uniform temperature region was detected at each temperature setting (the wall temperature). The temperature rapidly decreased before the heavy tar trap because of the secondary Ar. The heating rate of the basket increased with the reactor temperature. The maximum heating rates of the basket were 36,50 and $56 \mathrm{~K} / \mathrm{s}$ for the different reactor temperatures $(873,1073$, and $1173 \mathrm{~K}$, respectively). The temperature profiles under an Ar/steam atmosphere were nearly the same.

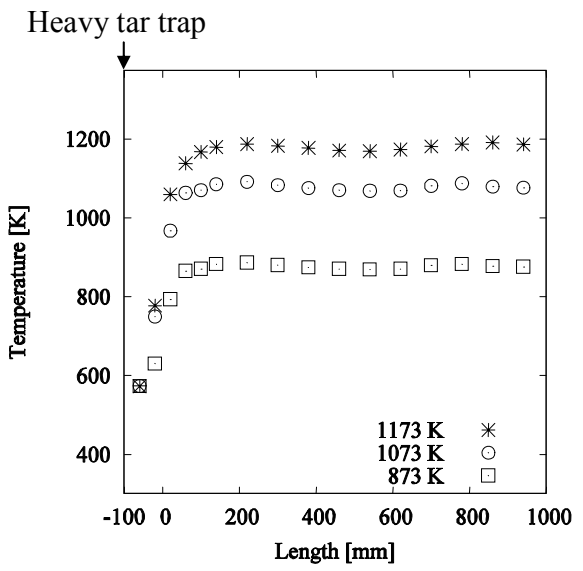

Figure 2 Temperature profiles in the reactor

Figure 3 shows a comparison of the spectra of the light (a) and middle (b) tars. Tar components with molecular weights less than 78 were rarely observed in the middle tar. The heavy tar spectrum was not measured; however, chemical species with high molecular weights were expected to be found in the heavy tar. Meanwhile, a wide range of chemical components was observed in the light tar. In this study, tars, that were not completely collected in the heavy and middle tar traps, were collected in the light tar trap; however, the chemical species in the tars were separated to a certain degree using the different temperature filters.
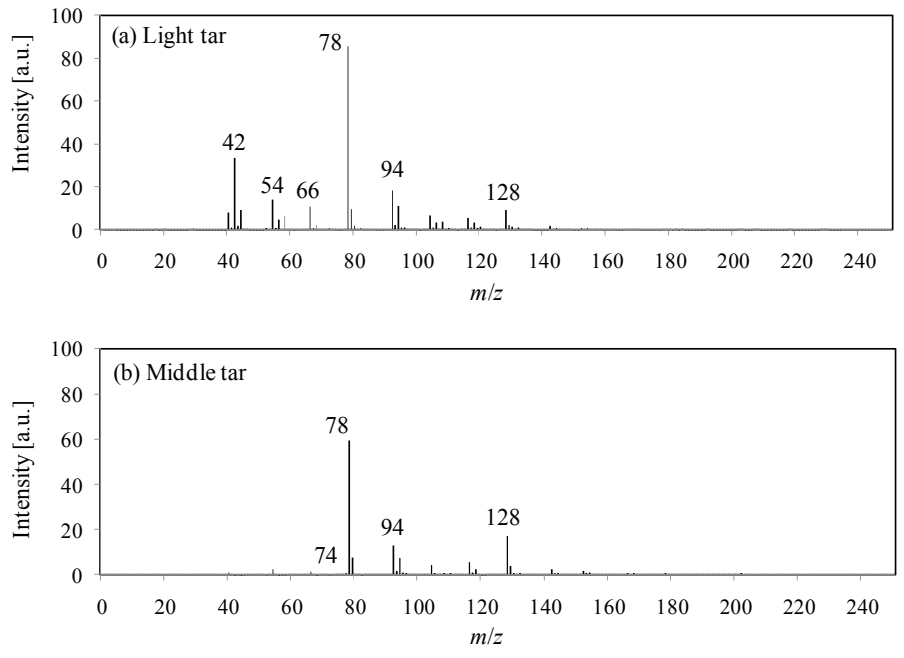

Figure 3 Comparison of tar spectra $(973 \mathrm{~K}, 3 \mathrm{~s})$ 
Figure 4 shows the product yields under Ar at $3 \mathrm{~s}$. The total yields at all-temperatures was greater than $85 \mathrm{wt} \%$. As shown in Figure 4(a), the total yield increased with temperature, with a total yield of nearly $100 \mathrm{wt} \%$ at $1173 \mathrm{~K}$. This result indicates that the number of chemical species undetectable by the gas chromatographs decreased with increasing temperature owing to the thermal cracking of these species. The main gaseous components were $\mathrm{CO}, \mathrm{CH}_{4}$ and $\mathrm{CO}_{2}$ (Figure 4(b)). The gas yield increased with temperature, even though the undetectable species were assumed to be gaseous products. This will be discussed later.
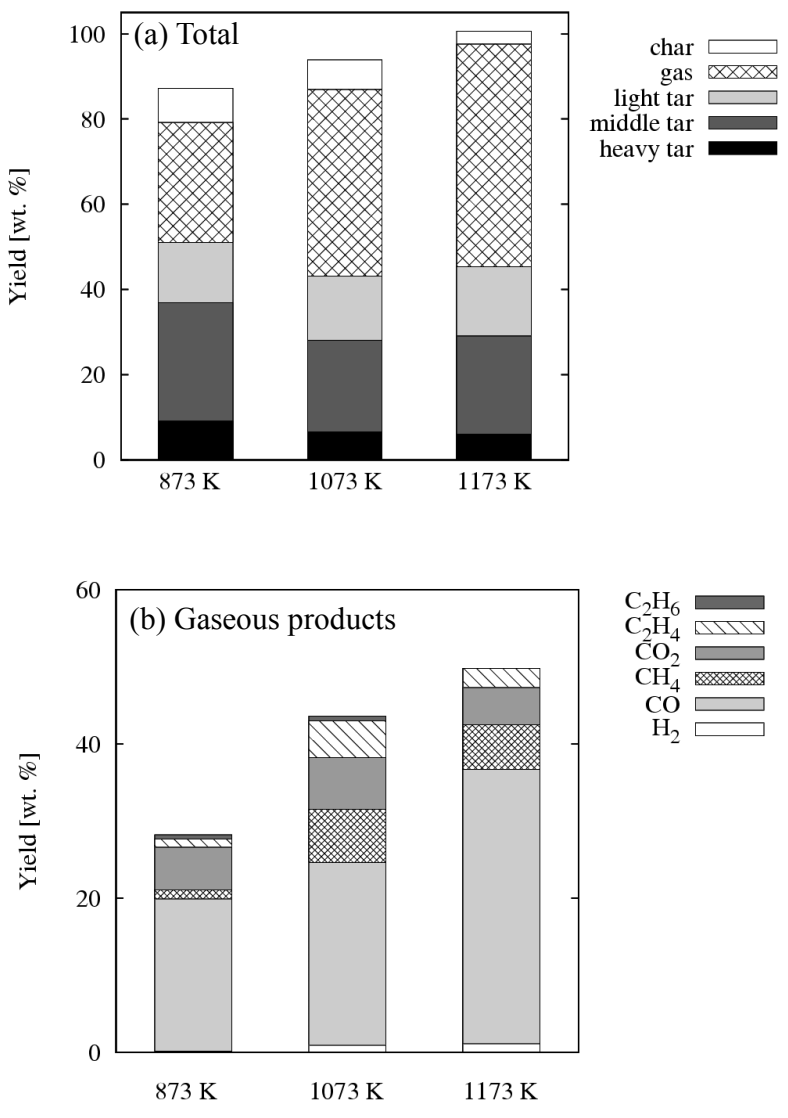

Figure 4 Product yields under Ar at residence time of $3 \mathrm{~s}$

Figure 5 shows all-tar histories at different temperatures under an Ar atmosphere. Each tar showed different formation and decomposition characteristics. The middle and light tars decreased with increasing residence time because of the thermal cracking. An interesting finding was that the formation of heavy tar was quite different from those of both middle and light tars. At $873 \mathrm{~K}$, the heavy tar yield did not vary regardless of the residence time. However, with increasing temperature, the heavy tar yield initially increased, and then gradually decreased. This result indicates that the heavy tar is formed not only by cellulose pyrolysis but also the polymerization of the middle and light tars, which is progressed with elapsed time, at 1073 and $1173 \mathrm{~K}$, respectively.

By linear extrapolation of the measured tar yields, the yields of the heavy and light tars at $0 \mathrm{~s}$ were predicted, as shown in Figure 6. Therefore, the effect of tar polymerization is not appeared in Figure 6. With increasing temperature, the heavy tar yield decreased, while that of the light tar increased. It has been claimed that levoglucosan or other heavy tar species is reduced at higher temperatures, in contrast to the other light products. During pyrolysis, many reactions with different reaction rates, such as dehydration to form cross-linked structures and depolymerization (the splitting of glycosidic bonds), proceed simultaneously. 
Balat et al showed that important reactions occur at different temperatures ${ }^{(22)}$. The production of tar products is maximized at temperatures between 625 and $725 \mathrm{~K}$, caused by the breaking of the glycosidic bonds of the polysaccharide ${ }^{(22,23)}$. Moreover, at temperatures above $725 \mathrm{~K}$, large molecules in the tar, which comprise the heavy tar in this study, are broken down to produce smaller molecules that enrich light tar components and gaseous products as a result of dehydration, rearrangement and scission of sugar units ${ }^{(22)}$. Slow heating rates imply long exposure times at low temperatures, while high heating rates mean short times at low temperatures and long times at high temperatures. Chaiwat et al. showed that, for tar products, a cross-linked dimer, which is expected to be present in the heavy tar in the study, was observed from slow pyrolysis ${ }^{(24)}$. Based on the above discussion, it can be concluded that high temperatures and a high heating rate inhibit the formation of heavy tar and enhance the light tar formation.
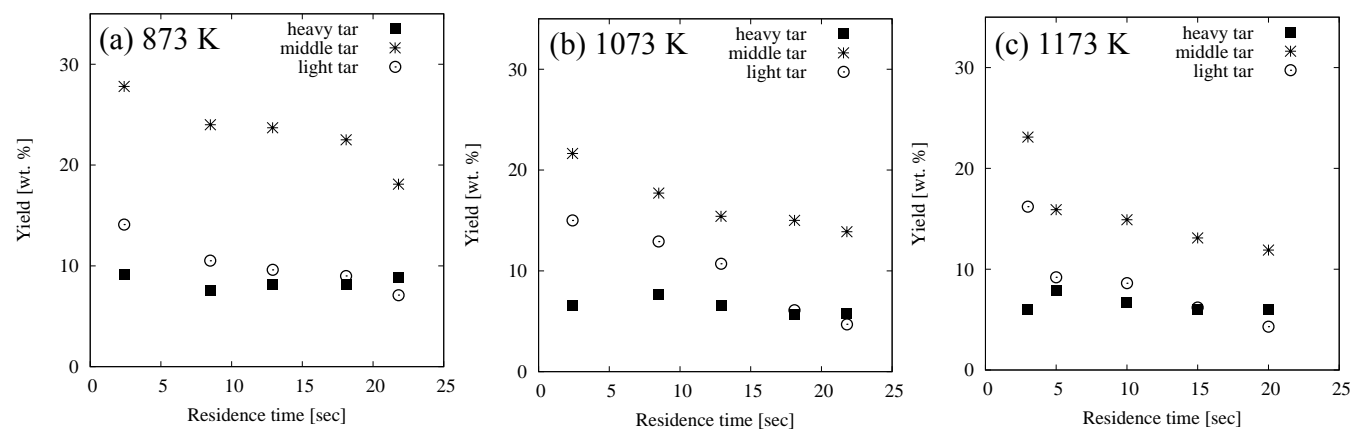

Figure 5 Tar histories under Ar atmosphere

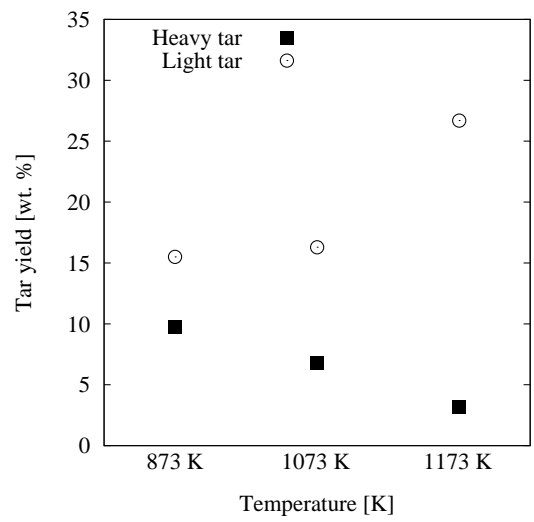

Figure 6 Predicted heavy tar yield at $0 \mathrm{sec}$

Figure 7 shows the effect of temperature on the yield of the heavy tar (a), the middle tar (b) and the gas (c) at $3 \mathrm{~s}$ under an Ar and Ar/steam atmosphere. In the steam experiment, the light tar weight was not measured because some amount of water was also trapped at the light tar filter. Both the heavy and the middle tar yields decreased under the Ar and Ar/steam atmospheres with increasing temperature. Although steam reformed the heavy tar at high temperature, the heavy tar was barely reformed at the low temperature of $873 \mathrm{~K}$. However, the steam-reforming characteristics of the middle tar were quite different from those of the heavy tar. Steam drastically reformed the middle tar, even at $1073 \mathrm{~K}$, as shown in Figure 7(b). The middle tar was reformed relatively easily, while the heavy tar was barely reduced by steam at low temperature. It can also be seen that the heavy tar formation was not favorable in low-temperature gasification. The light tar was not measured in the steam-reforming experiment; however, the light tar was expected to be reformed at a lower temperature because the molecular weights of the light tar species detected in the MS were 
similar to or less than those of the middle tar. The gas amount increases with increasing temperature under Ar and Ar/steam atmosphere as shown in Figure 7(c). The gas amount was the molar quantity of gas products in a gas pack $(5 \mathrm{~L})$. At the low temperature of $873 \mathrm{~K}$, the gas yield did not change significantly by adding steam. This result corresponded to the steam-reforming characteristics of the heavy and middle tars, which were not reduced by steam. However, the gas yield (mainly $\mathrm{CO}$ and $\mathrm{H}_{2}$ ) drastically increased over $1073 \mathrm{~K}$ by adding steam. In particular, $\mathrm{H}_{2}$ production increased at $1173 \mathrm{~K}$. The main tar reactions in a steam atmosphere are ${ }^{(2)}$ :

$$
\begin{array}{lll}
\operatorname{tar}+\mathrm{H}_{2} \mathrm{O} & \rightarrow \mathrm{CO}+\mathrm{H}_{2} & \text { (tar steam reforming) } \\
\mathrm{CO}+\mathrm{H}_{2} \mathrm{O} \rightarrow \mathrm{CO}_{2}+\mathrm{H}_{2} & \text { (water-gas shift) }
\end{array}
$$

The $\mathrm{H}_{2}$ yield increased above $1173 \mathrm{~K}$ because the water-gas shift reaction (2) proceeded at high temperature.
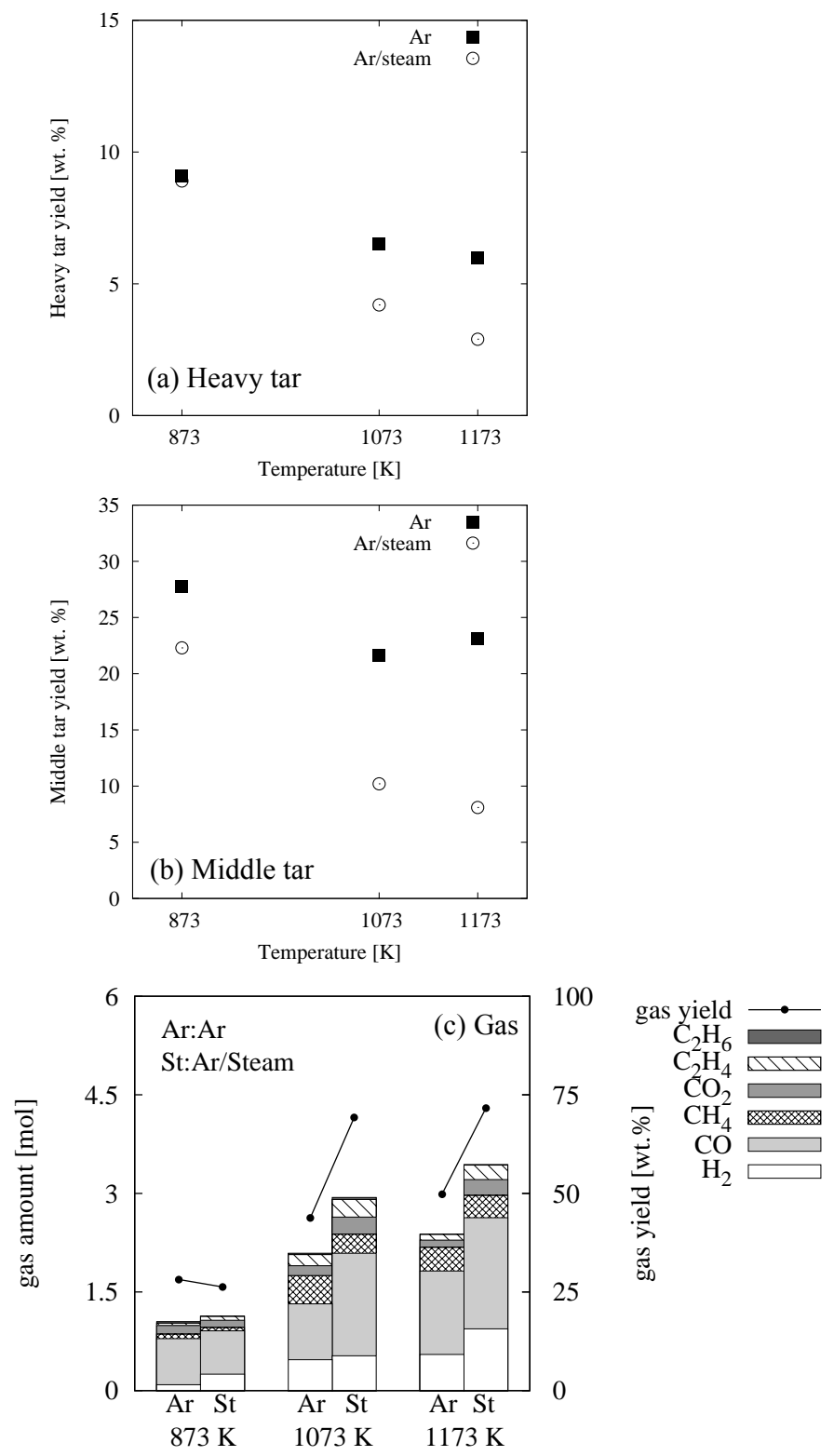

Figure 7 Comparison of heavy tar, middle tar, and gas yield between under Ar and $\mathrm{Ar} /$ steam at $3 \mathrm{~s}$ 
Figure 8 shows the effect of temperature on the heavy tar yield (a), the middle tar yield (b) and the gas yield (c) at $17 \mathrm{~s}$ under Ar and Ar/steam atmospheres. Even with a long residence time, the heavy tar barely reacted with steam at the low temperature of $873 \mathrm{~K}$, while $80 \%$ of the middle tar was reformed with the steam. The composition of the product gases was similar to that at $3 \mathrm{~s}$; however, the gas yield increased because of the progress of the tar reactions (1)-(2). Thus, it was shown that heavy tar formation during pyrolysis should be inhibited by increasing the heating rate to prevent tar emissions.
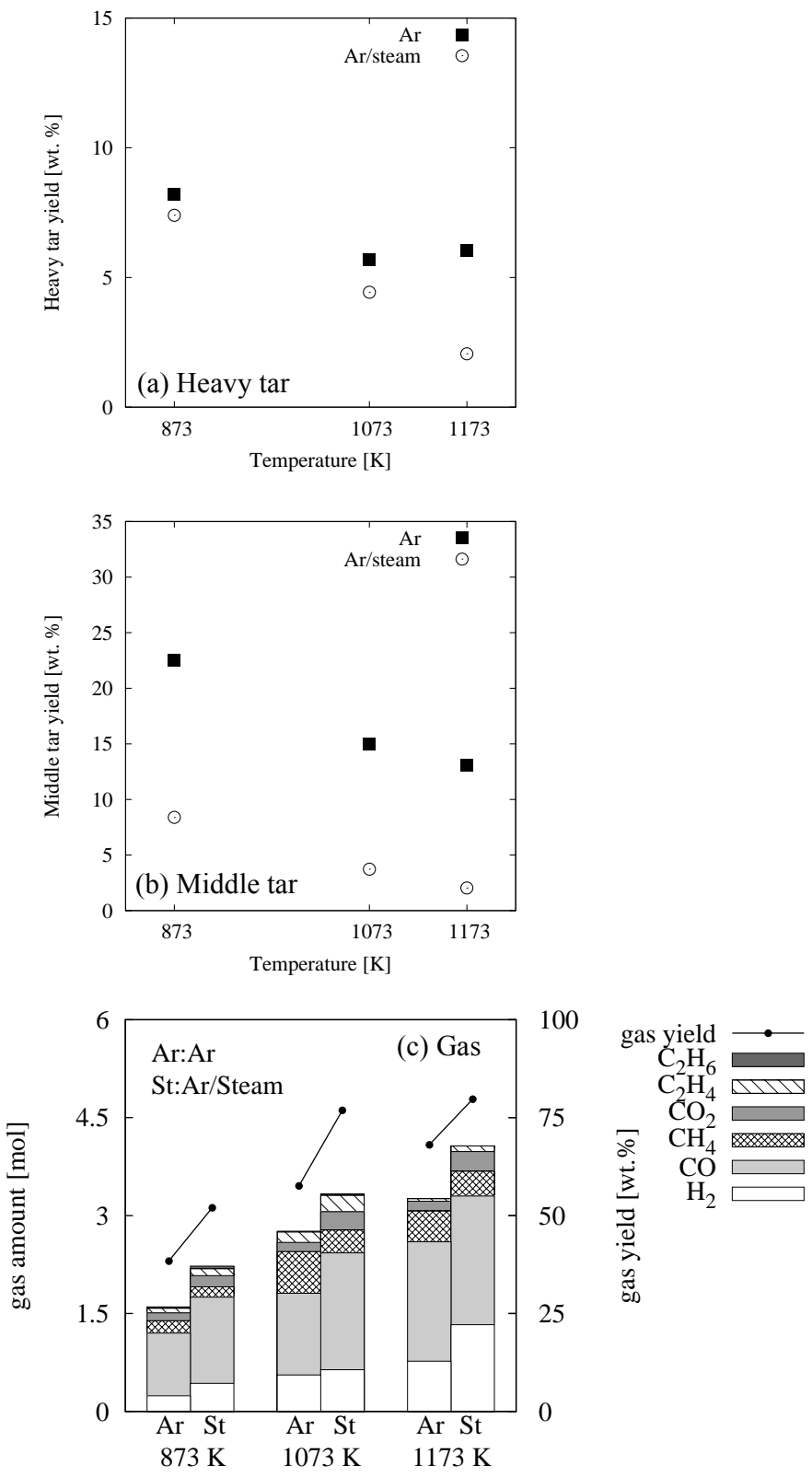

Figure 8 Comparison of heavy tar, middle tar, and gas yield between under Ar and $\mathrm{Ar} / \mathrm{steam}$ at $17 \mathrm{~s}$

\section{Conclusion}

In this study, a basket with cellulose was rapidly heated by dropping it into a high-temperature reactor. Then, the released tars were trapped at filters set at different temperatures $(573,393$, and $273 \mathrm{~K})$, respectively identified as heavy, middle, and light tars. 
Gaseous products were measured using GC-TCD and GC-FID. The tar formation characteristics and steam-reforming sensitivity of each tar were discussed. It was shown that the formation characteristics of each tar were quite different. With increasing temperature, the formation of heavy tar was inhibited, while that of the light tar was enhanced. The steam-reforming characteristics of these tars were also different. The heavy tar was barely reformed at the low temperature of $873 \mathrm{~K}$, even after a long residence time, while the middle tar was well reformed by steam. When tar was considered to be a single condensable matter, it was difficult to describe its formation and steam-reforming characteristics. However, these characteristics were clarified in this study by separating the tars. Low-temperature gasification is desirable for high-efficiency biomass gasification. Therefore, it is appropriate that the formation of heavy tar, which barely reacts with $\mathrm{H}_{2} \mathrm{O}$, is inhibited during biomass pyrolysis. This study shows that heavy tar formation during pyrolysis should be inhibited by controlling the heating to prevent tar emission.

\section{References}

(1) Devi, L., Ptasinski, K. J., Janssen, F. J., "Pretreated olivine as tar removal catalyst for biomass gasifiers: investigation using naphthalene as model biomass tar", Fuel Process Technol., 86 (2005) 707-730.

(2) Garcia, L., Salvador, M. L., Arauzo, J., Bilbao, R., "Catalytic Steam Gasification of Pine Sawdust. Effect of Catalyst Weight/Biomass Flow Rate and Steam/Biomass Ratios on Gas Production and Composition", Energy Fuels, 13(1999) 851-859.

(3) Wang, T., Chang, J., Lv, Pengmei., Zhu, J., "Novel Catalyst for Cracking of Biomass Tar", Energy Fuels, 19 (2005), 22-27.

(4) Cao, Y., Wang, Y., Riley, J., Pan, W. P., "A novel biomass air gasification process for producing tar-free higher heating value fuel gas", Fuel Process Technol., 87 (2006) 343-353.

(5) Wei, L., Xu. S., Zhang, L., Liu, C., Zhu, H., Liu, S., "Steam gasification of biomass for hydrogen-rich gas in a free-fall reactor", Int. J. Hydrogen Energy, 32 (2007) 24-31.

(6) Chaiwat, W. Hasegawa, I., Mae, K., "Alternative Reforming Methods of Primary Tar Released from Gas Treatment of Biomass at Low Temperature for Development of Pyrolysis/Gasification Process", Ind. Eng. Chem. Res., 49 (2010) 3577-3584.

(7) Okekunle, O. P., Watanabe, H., Pattanotai, T., Okazaki, K., "Effect of Biomass Size and Aspect Ratio on Intra-Particle Tar Decomposition during Wood Cylinder Pyrolysis", J. Therm. Sci. Technol., 7 (2012) 1-15.

(8) Simell, P. A., Hirvensalo, E. K., Smolander, V. T., "Steam Reforming of Gasification Gas Tar over Dolomite with Benzene as a Model Compound", Ind. Eng. Chem. Res., 38 (1999) 1250-1257.

(9) Simell, P. A., Hepola, J. O., Krause, A. O., "Effects of gasification gas components on tar and ammonia decomposition over hot gas cleanup catalysts", Fuel, 76 (1997) 1117-1127. (10) Swierczynski, D., Libs, S., Courson, C., Kiennemann, A., "Steam reforming of tar from a biomass gasification process over Ni/olivine catalyst using toluene as a model compound", App Catal B Env, 74 (2007) 211-222.

(11) Zhao, H., Draelants, D. J., Baron, G. V., "Performance of a Nickel-Activated Candle Filter for Naphthalene Cracking in Synthetic Biomass Gasification Gas", Ind. Eng. Chem. Res., 39 (2000) 3195-3201.

(12) Gayubo, A. G., Aguayo, A. T., Atutxa, A., Prieto, R., Bilbao, J., "Deactivation of a HZSM-5 Zeolite Catalyst in the Transformation of the Aqueous Fraction of Biomass Pyrolysis Oil into Hydrocarbons", Energy Fuels, 18 (2004) 1640-1647.

(13) Shen, D. K.; Gu, S. "The mechanism for thermal decomposition of cellulose and its main products", Bioresource Technol., 100 (2009) 6496-6504.

(14) Hosoya, T., Kawamoto, T., Saka, S., "Secondary reactions of lignin-derived primary tar components", J. Anal. App. Pyrolysis, 83 (2008) 78-87.

(15) Fushimi, C., Araki, K., Yamaguchi, Y., Tsutsumi, A., "Effect of Heating Rate on Steam 
Gasification of Biomass. 2. Thermogravimetric-Mass Spectrometric (TG-MS) Analysis of Gas Evolution", Ind. Eng. Chem. Res., 42(2003) 3922-3928.

(16) Brand, P., Larsen, E., Henriksen, U., "High Tar Reduction in a Two-Stage Gasifier", Energy Fuels, 14 (2000) 816-819.

(17) Gilbert, P., Ryu, C., Sharifi, V., Swithenbank, J., "Tar reduction in pyrolysis vapours from over a hot char bed", Bioresource Technol., 100, (2009) 6045-6051.

(18) Mansur, D., Yoshikawa, T., Norinaga, K., Hayashi, J., Tago, T., Masuda, T., "Production of ketones from pyroligneous acid of woody biomass pyrolysis over an iron-oxide catalyst", Fuel (2012), in press.

(19) Park W.C. et al., "Experimental and theoretical investigation of heat and mass transfer processes during wood pyrolysis" Combust. Flame, 157 (2010), 481- 494.

(20) Luo, Z.; Wang, S.; Liao, Y.; Cen, K. "Mechanism Study of Cellulose Rapid Pyrolysis", Ind. Eng. Chem Res, 43 (2004), 5605-5610.

(21) Lede, L., Diebold, J. P., Peacocke, G. V. C., Piskorz, J. Developments in thermochemical biomass conversion; Blackie Academic \& Professional; Great Britain, 1997: p. 38

(22) Balat, M., Balat, M., E. Kirtay, H., Balat, H., "Main routes for the thermo-conversion of biomass into fuels and chemicals. Part 1: Pyrolysis systems", Energy Convers. Manage., 50 (2009) 3147-3157.

(23) Maschio, G., Koufopanos, C., Lucchesi, A., "Pyrolysis, a promising route for biomass utilization", Bioresource Technol., 42 (1992) 219-231.

(24) Chaiwat, W., Hasegawa, I., Tani, T., Sunagawa, K., Mae, K., "Analysis of Cross-Linking Behavior during Pyrolysis of Cellulose for Elucidating Reaction Pathway", Energy Fuels, 23 (2009) 5765-5772. 